\title{
INFLUÊNCIA DA ADIÇÃO DO RESÍDUO DE CORTE DE MÁRMORE E GRANITO (RCMG) NA REOLOGIA DAS ARGAMASSAS
}

\author{
Gabriel Ricardo Silva Santos ${ }^{1}$ \\ Elenice Carmo de Abreu Apolinário ${ }^{2}$ \\ Daniel Véras Ribeiro ${ }^{3}$
}

RESUMO: A construção civil é a atividade que mais consome recursos não-renováveis em todo o planeta. Em contrapartida, possui a capacidade de incorporar rejeitos gerados por outras atividades, minimizando impactos oriundos de descartes inadequados e reduzindo o seu próprio consumo de matéria-prima. Nesse cenário está o resíduo de corte de mármore e granito (RCMG), o qual ainda não possui um destino adequado, sendo disposto indevidamente no meio ambiente, resultando em impactos ambientais que podem comprometer a flora e a fauna. Em matrizes cimentíceas, o RCMG tem a capacidade de agir como filler, ocupando os espaços vazios existentes em argamassas e concretos e, assim, modificando suas características reológicas. No presente estudo, foram adicionados teores de 5\%, 10\% e 15\% de resíduo, em relação à massa de cimento, em argamassas de cimento Portland. Em seguida, avaliaram-se a densidade de massa, 0 teor de ar incorporado, a retenção de água, além de suas propriedades reológicas, por meio da mesa de consistência, flow table, e do squeeze flow. Os resultados indicaram que a argamassa confeccionada com adição do resíduo de $10 \%$ apresentou o melhor desempenho, concluindo-se, então, que a utilização do RCMG é uma alternativa tecnicamente viável para adição a argamassas.

Palavras-chave: resíduo, mármore e granito, argamassas, reologia.

${ }_{1}^{1}$ Graduando em Engenharia Civil, Universidade Federal da Bahia, gricardo93@hotmail.com

${ }_{2}^{2}$ Mestranda pelo Mestrado em Engenharia Ambiental Urbana (MEAU), Universidade Federal da Bahia, eleapoli2000@yahoo.com.br

${ }^{3}$ Doutor em Ciência e Engenharia dos Materiais, Universidade Federal da Bahia, verasribeiro@hotmail.com 


\section{INTRODUÇÃO}

O Brasil passa por um momento de grande crescimento econômico e, consequentemente, a construção civil acompanha este ritmo. Segundo o IBGE, em 2010 foram investidos cerca de 260 bilhões de reais nesse setor, impulsionado por uma maior facilidade nos empréstimos provenientes dos recursos do FGTS, grandes eventos como Jogos Pan-Americanos, Olimpíadas e Copa do Mundo, além de programas do governo, por exemplo: PAC I, PAC II. Nesse cenário, cresce também a quantidade de resíduos gerados por essa indústria, bem como a preocupação em oferecer uma destinação adequada para eles.

Outra preocupação é o fato de que a indústria da construção civil é a principal atividade consumidora dos recursos naturais que são extraídos anualmente e estima-se que entre 20 e 50\% são incorporados a esta cadeia (SJÖSTRÖM, 1992). Isso gera uma pressão para que essa indústria tome medidas mais eficazes acerca da diminuição do uso de recursos naturais, da busca por novos materiais de maior eficiência e do descarte e reaproveitamento dos resíduos gerados pela sua atividade (ÂNGULO et al., 2001).

O resíduo de corte de mármore e granito (RCMG) é gerado durante a etapa de beneficiamento na produção de rochas ornamentais, na qual grandes blocos de mármore e granito são serrados por teares, gerando, além do resíduo do corte, granalha, cal e água. O resultado é uma lama abrasiva capaz de levar rios, lagos, córregos e até reservatórios naturais de água a altos níveis de contaminação (SIMSEK apud MANHÃES \& HOLANDA, 2009). Esse resíduo possui grande potencial para adição a matrizes cimentíceas, pois possui elevada estabilidade e resistência à abrasão (APOLINÁRIO et al., 2013). Por ser um material fino, espera-se que sua adição modifique significativamente as propriedades reológicas das argamassas. 


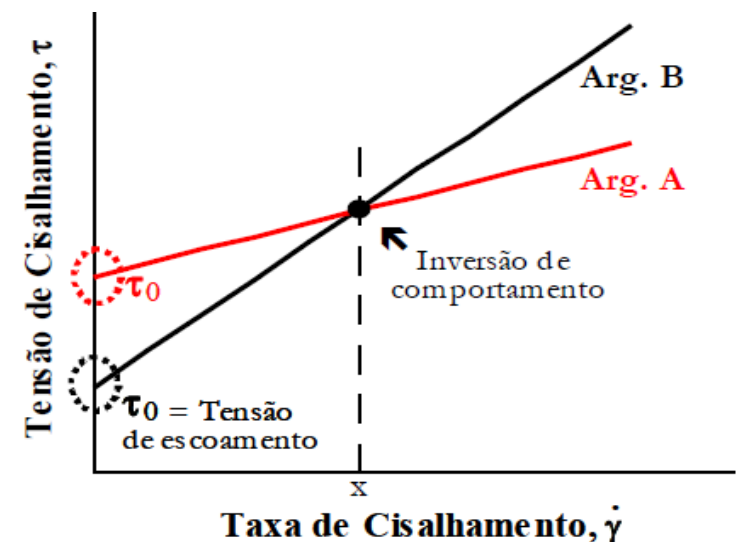

Figura 1 - llustração esquemática de argamassas com comportamento de fluido de Bingham (CARDOSO, 2009; BANFILL, 2005)

Através de uma abordagem simplificada, as argamassas frescas costumam ser consideradas fluidos de Bingham (BANFILL, 2006; SENFF et al., 2010; RIBEIRO, 2013), ou seja, materiais que apresentam uma tensão mínima para iniciar o escoamento (tensão de escoamento) e, em fluxo, têm uma relação linear entre tensão e taxa de cisalhamento (Fig. 1).

No modelo de uma suspensão, admite-se que o fluido adicionado recobre primeiramente a superfície das partículas sólidas para depois preencher o volume de vazios deixado pelo empacotamento dessas partículas (PILEGGI, 2001), conforme Figura 2.
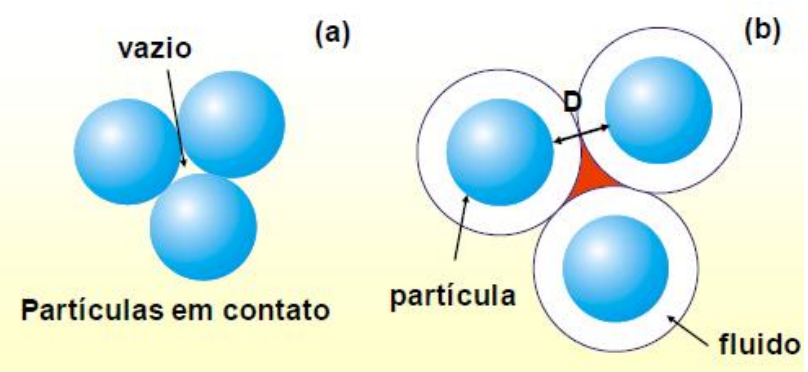

Figura 2 - Mecanismo de preenchimento dos espaços entre partículas em uma suspensão por um fluido. (a) Partículas em contato; (b) Partículas separadas em decorrência da adição do fluido que recobre a superfície das partículas para então preencher os espaços vazios e separar as partículas (PILEGGI, 2001).

A distância entre as partículas influencia significativamente o comportamento reológico das suspensões, apresentando uma relação direta com a fluidez (CARDOSO, 2009). Quanto menor a porosidade do sistema, definida pela distribuição granulométrica, 
mais facilmente o fluido conseguirá afastar as partículas, melhorando a fluidez. A área superficial atua de maneira contrária, quanto maior for o seu valor, uma maior quantidade de fluido é necessária para recobrir as partículas e assim menor será o afastamento das partículas, assim como a fluidez do sistema.

Em materiais como argamassas, o comportamento reológico é bastante influenciado por parâmetros como a viscosidade da pasta, o teor de ar incorporado e o próprio efeito dos agregados, podendo este ser avaliado através da distância de separação entre essas partículas, de forma análoga a uma suspensão. Quanto maior essa distância, menores serão as forças de atrito restritivas ao fluxo da argamassa e, então, mais fácil será deformá-la.

Este trabalho teve como objetivo avaliar a viabilidade técnica do uso do resíduo de corte de mármore e granito (RCMG) como adição a argamassas de cimento Portland, observando se sua adição pode comprometer seu comportamento reológico. Foram adotados teores de 5\%, 10\% e 15\% de adição do resíduo, em relação à massa de cimento, para argamassas de cimento e areia sem o uso de aditivos. Estas foram analisadas quanto ao seu comportamento reológico. Os resultados permitiram verificar o efeito da adição nas principais propriedades das argamassas, assim como identificar o teor ótimo de adição às argamassas.

\section{MATERIAIS E MÉTODOS}

\subsection{Materiais}

Foram utilizados o cimento CP-II Z 32 RS da marca Poty, areia natural quartzosa, resíduo de corte de mármore e granito (RCMG) e água proveniente da rede pública de abastecimento da Empresa Baiana de Água e Saneamento S.A. - Embasa.

O resíduo, coletado na forma de lama, foi gerado durante a etapa de corte das rochas e é formado por uma proporção não definida de mármore e granito. Assim, sua composição química pode apresentar variabilidade a depender do lote em estudo, como é comum ao tratar-se de resíduos de processos industriais. 


\subsubsection{Caracterização das Matérias-Primas}

A análise granulométrica da areia foi realizada através de peneiramento manual conforme a NBR NM 248:2003 ("Agregados - Determinação da composição granulométrica"), a massa específica foi determinada pelo método do frasco de Chapman e a massa unitária pelo procedimento da NBR NM 45:2006 (“Agregados - Determinação da massa unitária e do volume de vazios").

A caracterização física do cimento CP II Z 32 RS e a do RCMG foram realizadas pelo Laboratório de Formulação e Síntese Cerâmica da Universidade Federal de São Carlos (LAFSCer - UFSCar). A massa específica foi obtida mediante a um picnômetro a gás hélio, a distribuição do tamanho de partículas foi obtida com o auxílio de um sedígrafo - Horiba CAPA-700 - e a área superficial BET com o auxílio do aparelho Gemini 2370 V1.02, da Micrometrics. A caracterização mineralógica foi determinada por difração de raios-X (DRX), através de um difratômetro - Rigaku Geirgeflex ME 210GF2 - pertencente ao Instituto de Física da Universidade de São Paulo (IFUSP), e a composição química foi determinada pelo SGS GEOSOL Laboratórios Ltda., por meio da técnica de fluorescência de raios- $X(F R X)$.

\subsubsection{Formulação e Preparo das Argamassas}

Definiu-se, inicialmente, o traço $1,00: 2,60: 0,59$ (cimento : areia : água), sobre o qual foi acrescida a quantidade de resíduo referente a cada composição $(0 \%$ - referência -, 5\%, 10\% e 15\%, em relação à massa de cimento). A relação água/cimento foi mantida constante (igual a 0,59) e não foram empregados aditivos para uniformização da consistência.

As misturas foram realizadas mecanicamente, em uma argamassadeira, durante um tempo de 90 segundos, de acordo com a NBR 13276:2006 ("Argamassa para assentamento e revestimento de paredes e tetos - Preparo da mistura e determinação do índice de consistência"). 


\section{Sacen

\subsubsection{Análise de Desempenho}

a) Densidade de massa e teor de ar incorporado (NBR 13278:2005)

A densidade de massa no estado fresco fornece indícios acerca da trabalhabilidade e produtividade do aplicador na execução do revestimento. Quanto menos densa for a argamassa, menor esforço do operário na sua aplicação, resultando em um aumento de produtividade ao final da jornada de trabalho (CARASEK, 2007).

O teor de ar incorporado está diretamente associado à densidade de massa das argamassas. A presença de ar influencia o comportamento no estado fresco das argamassas, tornando-o mais complexo, já que apresenta uma fase a mais na mistura (CARDOSO, 2009).

O ensaio, conforme NBR 13278:2005 ("Argamassa para assentamento e revestimento de paredes e tetos - Determinação da densidade de massa e do teor de ar incorporado"), consiste em determinar o valor de densidade de massa da argamassa e o teor de ar incorporado, a partir da densidade prática e da densidade teórica. Para a execução do ensaio, são introduzidas porções de argamassa em um recipiente cilíndrico de PVC, aplicando-se golpes ao longo do perímetro da argamassa a fim de adensá-la.

Assim, calculam-se a densidade de massa (Eq. 1) e o teor de ar incorporado (Eq. 2).

$$
\begin{gathered}
A=\frac{M c-M v}{V r} \\
A I=100 \cdot\left(1-\frac{A}{B}\right)
\end{gathered}
$$

onde, A é a densidade de massa da argamassa, Mv, a massa do recipiente vazio, Mc, a massa do recipiente contendo a argamassa e $\mathrm{Vr}$, o volume do recipiente. Al é a teor de ar incorporado e B é a densidade de massa teórica da argamassa sem vazios, calculada através da equação 3. 


$$
B=\frac{\Sigma M i}{\Sigma \frac{M i}{Y i}}
$$

onde, Mi é a massa seca de cada componente da argamassa, inclusive massa da água e yi, a massa específica de cada componente da argamassa.

\section{b) Índice de retenção de água (NBR 13277:2005)}

A retenção de água $(R a)$ é uma propriedade que está associada à capacidade da argamassa fresca manter a sua trabalhabilidade quando sujeita a solicitações que provocam perda de água de amassamento, seja por evaporação ou pela absorção de água da base (CARASEK, 2007). Após o endurecimento, as argamassas dependem de uma adequada retenção de água, para que as reações químicas de endurecimento dos aglomerantes se efetuem de maneira apropriada.

O ensaio, conforme NBR 13277:2005 ("Argamassa para assentamento e revestimento de paredes e tetos - Determinação da retenção de água") se inicia com a aferição da massa do conjunto formado pelo funil de Buchner e um disco de papel filtro levemente umedecido ( $\mathrm{Mv}$, massa do conjunto vazio). Em seguida, o funil é preenchido com argamassa e o adensamento é feito a golpes de soquete e o conjunto é novamente pesado ( $\mathrm{Ma}$, massa do conjunto com argamassa). Com o auxílio de uma bomba de vácuo, é aplicada uma pressão negativa correspondente a $51 \mathrm{~mm}$ de mercúrio durante 15 minutos. Decorrido o tempo de ensaio, determina-se a massa do conjunto com a argamassa (Ms, massa do conjunto após 15 minutos).

Utilizam-se as equações 4 e 5 para o cálculo do índice de retenção de água (Ra).

$$
\begin{gathered}
R a(\%)=\left[1-\frac{M a-M s}{A F \cdot(M a-M v)}\right] \cdot 100 \\
A F=\left[\frac{M w}{M+M w}\right]
\end{gathered}
$$


onde, M é a massa de argamassa industrializada ou soma das massas dos componentes anidros, no caso de argamassa de obra, e Mw a massa total de água.

\section{c) Caracterização reológica por meio da mesa de consistência (Flow Table) (NBR} 13276:2010)

Para o ensaio, conforme a NBR 13276 (“Argamassa para assentamento e revestimento de paredes e tetos - Preparo da mistura e determinação do índice de consistência"), a argamassa é utilizada para encher um molde tronco-cônico, colocado de modo centralizado sobre a mesa para índice de consistência. São aplicados 30 golpes na mesa de ensaio e imediatamente após o último golpe na mesa, mede-se o diâmetro de espalhamento da argamassa. O índice de consistência da argamassa corresponde à média de três medidas de diâmetro.

Esse método apresenta a vantagem de ser dinâmico, considerando tanto a viscosidade do sistema como a tensão de escoamento, contudo não dissocia a contribuição individual desses parâmetros. Além disso, avalia qualitativamente a tendência à segregação de fases no sistema, em decorrência da aplicação de energia (CARDOSO et al., 2008).

Cabe salientar, no entanto, que o flow table não avalia e nem serve para definir completamente a trabalhabilidade. É possível que duas argamassas tenham resultados iguais de consistência pelo flow table e uma delas apresente excelente trabalhabilidade enquanto a outra chegue ao ponto de não ser aplicável (CARASEK, 2007).

Por isso, o comportamento reológico de uma argamassa não pode ser descrito por um único valor de medida, mas sim por um perfil reológico medido com precisão e, de preferência, simulando as solicitações práticas reais, visto que o comportamento pode variar em função das características da solicitação, como tensão e taxa de cisalhamento e restrição do material (CARDOSO et al., 2008).

\section{d) Caracterização reológica pelo método do squeeze flow (NBR 15839)}

O squeeze flow baseia-se na medida do esforço necessário para a compressão uniaxial de uma amostra cilíndrica da argamassa entre duas placas paralelas. A 
configuração experimental adotada para a execução do ensaio de squeeze flow em argamassas, conforme a NBR 15839:2010 ("Argamassa de assentamento e revestimento de paredes e tetos - Caracterização reológica pelo método squeeze flow') consiste em aplicar a compressão através de uma placa superior, cujo diâmetro é igual ao diâmetro inicial da amostra, sobre uma placa inferior com diâmetro pelo menos duas vezes maior (Fig. 3). Esta é uma configuração que se assemelha com a aplicação prática das argamassas e facilita o cálculo dos níveis de tensão.

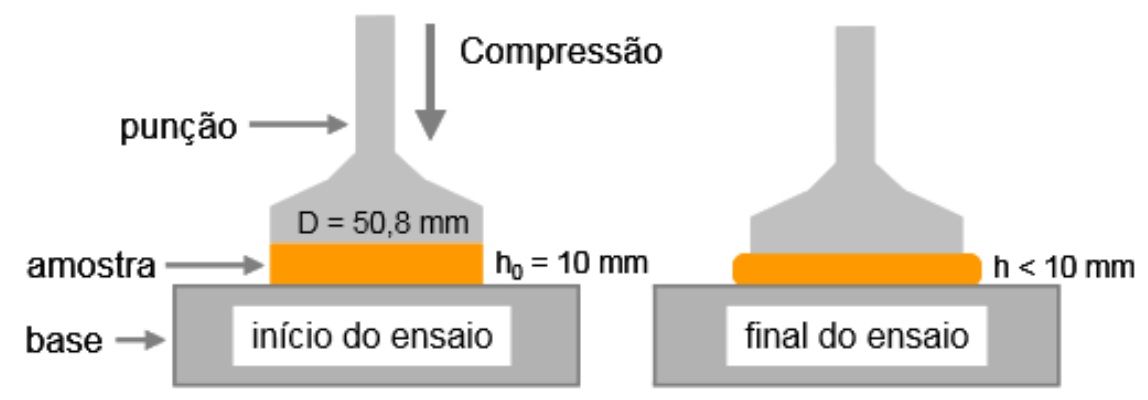

Figura 3 - Representação esquemática do ensaio reológico de squeeze flow, identificando a condição de início e final de ensaio. $\mathrm{D}$ = diâmetro do punção (placa superior) = diâmetro da amostra; h0 = distância inicial entre o punção e a base (placa inferior) = altura inicial da amostra; $\mathrm{h}$ = altura da amostra variável em função do deslocamento do punção superior. (CARDOSO et al., 2008)

O perfil típico obtido em um ensaio de squeeze flow com controle por deslocamento, expresso na forma de carga em função do deslocamento apresenta 3 regiões bem definidas, conforme Figura 4 (CARDOSO; PILEGGI; JOHN, 2008).

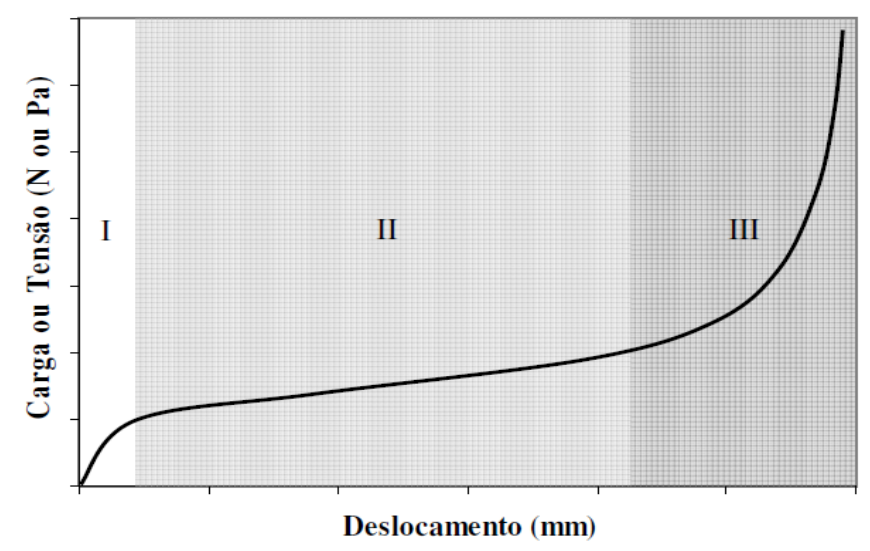

Figura 4 - Perfil típico de carga vs. deslocamento de um ensaio de squeeze flow realizado com velocidade controlada. (CARDOSO et al., 2008) 
No primeiro estágio, o material se comporta como um sólido em pequenas deformações, apresentando deformação elástica linear. Uma argamassa que apresente comportamento com uma parcela significativa nesse estágio possivelmente apresentará problemas de fissuração ainda no estado fresco devido à recuperação elástica após a retirada do esforço.

No estágio seguinte, a compressão resulta em deformação radial elongacional e de cisalhamento, superando as forças que mantinham o material sob comportamento elástico, e assim, a argamassa flui por deformação plástica ou viscosa dependendo das suas características. Nesta etapa o material é capaz de sofrer grandes deformações sem aumento significativo da força necessária para o deslocamento, um comportamento favorável à aplicação de argamassas.

No último estágio, no qual o material é submetido a grandes deformações, pode ocorrer um aumento expressivo da carga necessária para o seu deslocamento. A aproximação das partículas gera forças restritivas ao fluxo devido à maior interação, embricamento ou entrelaçamento das unidades móveis.

O uso da técnica do squeeze flow para a avaliação reológica de argamassas e outros materiais de construção mostra ser bastante sensível e versátil, possibilitando a adequação da geometria de ensaio para materiais com características de consistência inicial e de aderência distintas. O teste é capaz de detectar pequenas alterações nas características reológicas dos materiais, fornecendo um perfil de comportamento de acordo com as solicitações impostas. Assim, este método possui grande potencial para a pesquisa e desenvolvimento em argamassas (CARDOSO et al., 2008).

Em todas as argamassas, as condições ambientais se mantiveram em um intervalo constante de $25 \pm 5^{\circ} \mathrm{C}$ e $65 \pm 5 \%$ de umidade. $\mathrm{O}$ tempo decorrido desde $\mathrm{O}$ término do preparo da argamassa até o início do ensaio do squeeze flow foi de 8 minutos.

\section{RESULTADOS E DISCUSSÃO}

\subsection{Caracterização das Matérias-Primas}


A areia natural utilizada possui massa unitária de $1,59 \mathrm{~kg} / \mathrm{dm}^{3}$, massa específica de 2,62 kg/dm³ , módulo de finura igual a 1,70, dimensão máxima característica de 2,36 $\mathrm{mm}$ e um teor de $1,3 \%$ de material pulverulento.

O cimento utilizado, CP-II Z 32 da marca Poty, apresentou área superficial de 1,09 $\mathrm{m}^{2} / \mathrm{g}$, massa unitária de $1,00 \mathrm{~kg} / \mathrm{dm}^{3}$ e massa específica de $3,25 \mathrm{~kg} / \mathrm{dm}^{3}$. Sua composição química é apresentada na Tabela 1, onde PF é a perda ao fogo.

Tabela 1 - Composição química do cimento CP-II Z 32, obtida por FRX.

\begin{tabular}{|c|c|c|c|c|c|c|c|c|c|}
\hline Constituinte & $\mathrm{CaO}$ & $\mathrm{SiO}_{2}$ & $\mathrm{Al}_{2} \mathrm{O}_{3}$ & $\mathrm{MgO}$ & $\mathrm{Fe}_{2} \mathrm{O}_{3}$ & $\mathrm{SO}_{3}$ & $\mathrm{~K}_{2} \mathrm{O}$ & $\mathrm{Na}_{2} \mathrm{O}$ & $\mathrm{PF}$ \\
\hline Teor $(\%)$ & 56,0 & 24,5 & 6,1 & 4,0 & 2,5 & 1,8 & 0,25 & 0,45 & 4,1 \\
\hline
\end{tabular}

A massa específica do RCMG é de $2,92 \mathrm{~kg} / \mathrm{dm}^{3}$ e sua área superficial, $3,54 \mathrm{~m}^{2} / \mathrm{g}$. Por ser muito fino e possuir grande área superficial, o resíduo tem a capacidade de absorver uma significativa quantidade de água. Na Figura 5 são apresentadas as curvas de distribuição de tamanho de partículas do resíduo, do cimento CP-II Z 32 e da areia. O diâmetro médio (D50) das partículas do RCMG é de $12 \mu \mathrm{m}$, ao passo que, para o cimento, esse valor é de $50 \mu \mathrm{m}$. O RCMG é, assim, mais fino que o cimento, apropriado para o uso como filler.

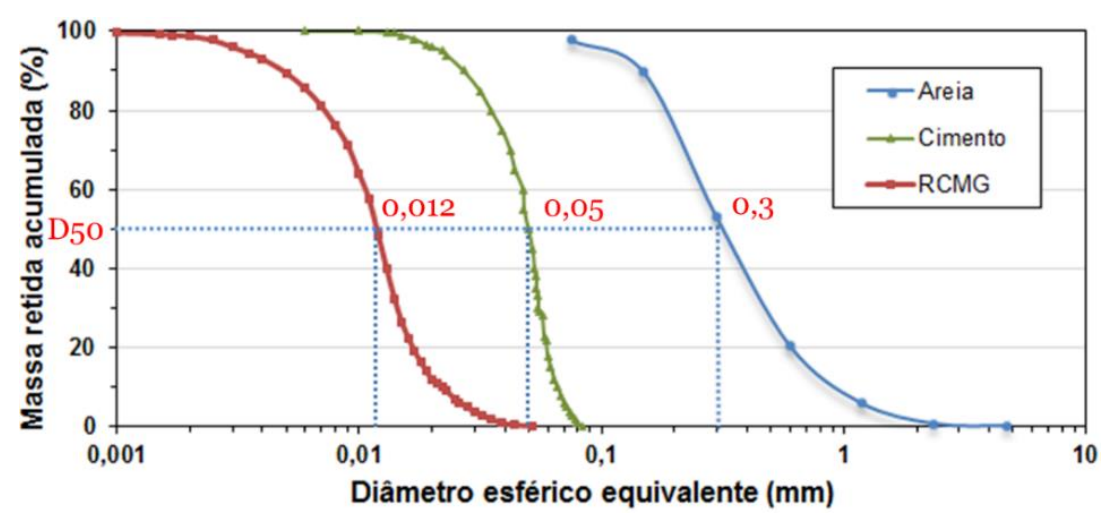

Figura 5 - Distribuição do tamanho de partículas do cimento Portland CP-II Z 32 RS da marca Poty e do RCMG, obtidos pelo ensaio de sedimentação, e a da areia, obtida pelo peneiramento manual.

A composição química do RCMG é apresentada na Tabela 2, onde observa-se a predominância da sílica $\left(\mathrm{SiO}_{2}\right)$, óxido de cálcio $(\mathrm{CaO})$ e alumina $\left(\mathrm{Al}_{2} \mathrm{O}_{3}\right)$ como seus 
principais constituintes, além do óxido férrico $\left(\mathrm{Fe}_{2} \mathrm{O}_{3}\right)$, proveniente do desgaste das lâminas de corte.

Tabela 2 - Composição química do RCMG, obtida por FRX.

\begin{tabular}{|c|c|c|c|c|c|c|c|c|c|}
\hline Constituinte & $\mathrm{CaO}$ & $\mathrm{SiO}_{2}$ & $\mathrm{Al}_{2} \mathrm{O}_{3}$ & $\mathrm{MgO}$ & $\mathrm{Fe}_{2} \mathrm{O}_{3}$ & $\mathrm{SO}_{3}$ & $\mathrm{~K}_{2} \mathrm{O}$ & $\mathrm{Na}_{2} \mathrm{O}$ & $\mathrm{PF}$ \\
\hline Teor (\%) & 56,0 & 24,5 & 6,1 & 4,0 & 2,5 & 1,8 & 0,25 & 0,45 & 4,1 \\
\hline
\end{tabular}

O arranjo desses elementos na formação de fases cristalográficas do material é ilustrado no difratograma de raios $X$ (Fig. 6). Constatou-se a ocorrência de minerais tipicamente componentes do granito, como quartzo $\left(\mathrm{SiO}_{2}\right)$, aluminossilicatos de cálcio $\left(\mathrm{CaAl}_{2} \mathrm{Si}_{2} \mathrm{O}_{8}\right)$ e flogopita (mineral da família das micas, classe dos filossilicatos, de fórmula química $\left.\mathrm{KMg}_{3}\left(\mathrm{Si}_{3} \mathrm{Al}\right) \mathrm{O}_{10}(\mathrm{OH})_{2}\right)$, assim como de dolomita, $\left(\mathrm{CaMg}\left(\mathrm{CO}_{3}\right)_{2}\right)$, devido à presença do pó de mármore.

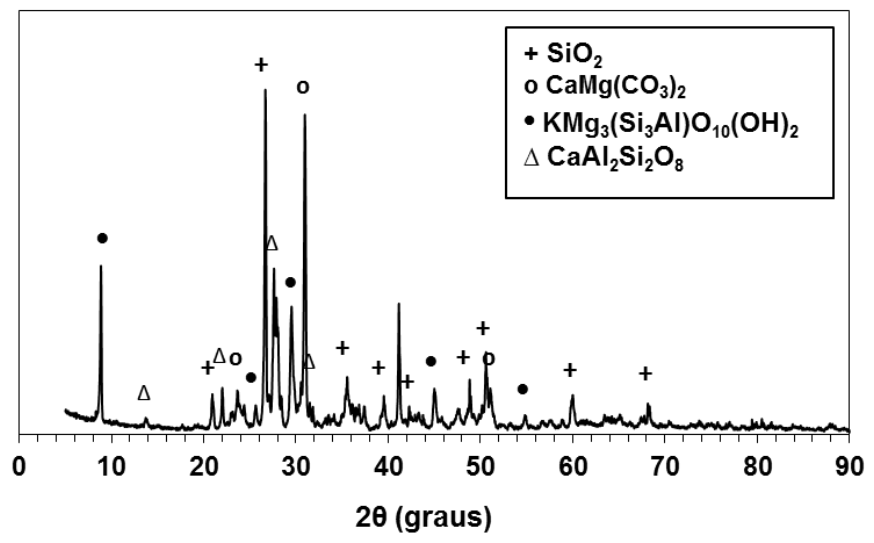

Figura 6 - Difratograma de raios-X do RCMG.

\subsection{Análise de Desempenho}

\subsubsection{Densidade de massa, teor de ar incorporado e índice de retenção de água}

A Tabela 3 apresenta os resultados de densidade de massa, teor de ar incorporado e retenção de água observados nas argamassas estudadas, em função do teor de RCMG adicionado. Conforme pode-se observar, a adição de RCMG conduziu ao aumento da densidade de massa e à diminuição do teor de ar incorporado pela melhora do empacotamento da mistura. 
Tabela 3 - Densidade de massa, teor de ar incorporado e índice de retenção de água das argamassas em função do teor de RCMG adicionado às argamassas.

\begin{tabular}{cccc}
\hline Teor RCMG & $\begin{array}{c}\text { Densidade Aparente } \\
\left(\mathrm{kg} / \mathrm{m}^{3}\right)\end{array}$ & $\begin{array}{c}\text { Teor de ar incorporado } \\
(\%)\end{array}$ & $\begin{array}{c}\text { Índice de retenção } \\
\text { de água }(\%)\end{array}$ \\
\hline $0 \%$ & 2113,23 & 4,2 & 84,1 \\
\hline $5 \%$ & 2135,71 & 3,5 & 83,5 \\
\hline $10 \%$ & 2138,29 & 3,7 & 83,4 \\
\hline $15 \%$ & 2146,96 & 3,5 & 81,4 \\
\hline
\end{tabular}

Conforme esperado, a densidade da argamassa no estado fresco cresceu conforme o aumento do teor de RCMG adicionado. Pelo fato do resíduo ser mais fino que a areia, suas partículas tendem a ocupar os espaços vazios na argamassa, refinando os poros e melhorando o empacotamento. Entretanto, foram observadas pequenas variações desse parâmetro (incremento máximo de 1,6\% para 15\% de RCMG) devido aos pequenos teores de adição de RCMG.

O teor de ar incorporado também foi pouco influenciado pelo RCMG, devido aos pequenos teores de adição, levando a uma tendência de diminuição dessa característica, sendo que a argamassa que apresentou a maior variação foi a que continha $15 \%$ de adição do resíduo. Resultados semelhantes também foram observados por Arnold \& Kazmierczak (2009) na adição de 10\% de filler em argamassas confeccionadas com areia de britagem.

Apesar da teórica tendência ao aumento da retenção de água, devido à elevada finura (elevada área superficial específica) do RCMG, não foi observada significativa influência sobre essa propriedade da argamassa, provavelmente devido ao fato de a adição ter sido feita em baixos teores, em relação à massa de cimento. A NBR 13281:2005 (Argamassa para assentamento e revestimento de paredes e tetos Requisitos) exige um índice mínimo de retenção de água de $78 \%$ para argamassas de assentamento e revestimento, valor que foi atingido por todas as argamassas.

Assim, pode-se concluir que para estes teores de adição, o RCMG não influi consideravelmente nas primeiras três propriedades analisadas. 


\subsubsection{Caracterização reológica}

\section{a) Índice de Consistência (Flow Table)}

O espalhamento das argamassas apresentou pequena variação, com os resultados estando compreendidos no intervalo de consistência igual $290 \pm 10 \mathrm{~mm}$, considerando que a adição de RCMG implicou na diminuição do índice de consistência (Fig 7).

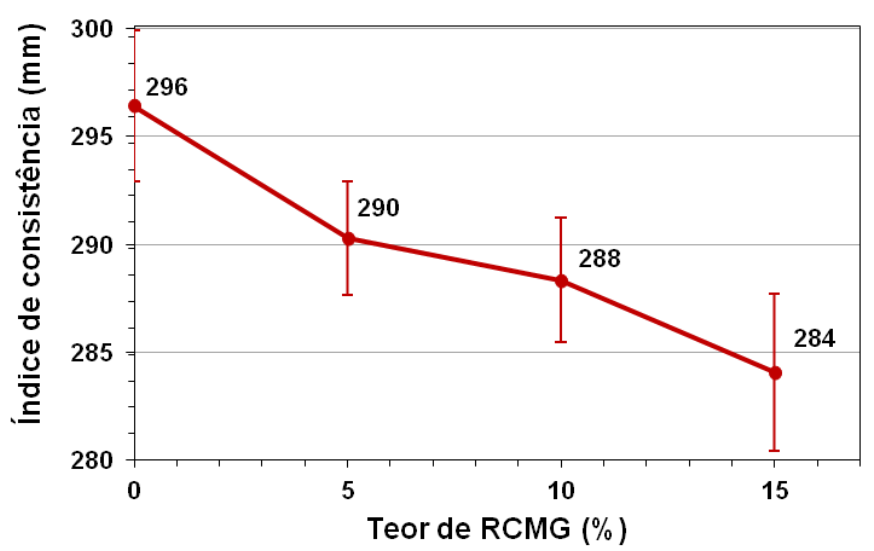

Figura 7 - Análise reológica das argamassas pelo método flow table, em função do teor de RCMG adicionado.

É importante ressaltar que os resultados obtidos pelo flow table não dissociam a contribuição de cada um dos parâmetros reológicos (viscosidade e tensão de escoamento) e não são apresentados em termos de unidades reológicas fundamentais (CARDOSO, 2005). Soma-se a isso o fato de que a fixação de determinado índice de consistência para a trabalhabilidade é incompleta (CAVANI; ANTUNES; JOHN, 1997), havendo variações conforme o tipo de argamassa.

\section{b) Squeeze Flow}

Com o squeeze flow, é possível a análise das propriedades reológicas das argamassas em condições que mais se assemelham às de aplicação. Observa-se na Figura 8 que a argamassa sem adição de RCMG exigiu maior carga para se deformar, apesar do maior índice de consistência, enquanto que as argamassas com adição se espalharam mais facilmente (ARNOLD; KAZMIERCZAK, 2009). 


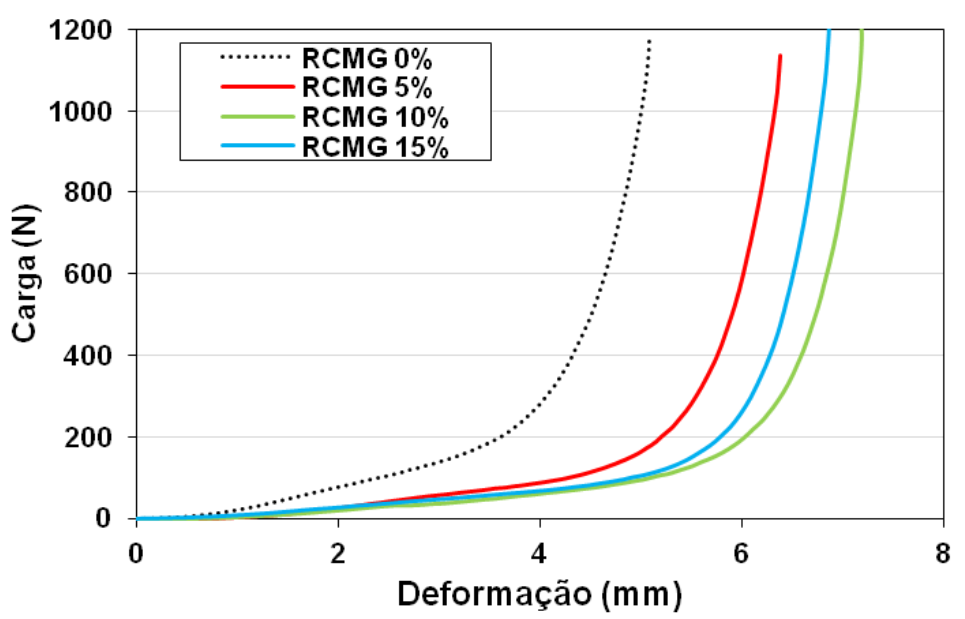

Figura 8 - Análise reológica das argamassas pelo método squeeze flow, em função do teor de RCMG adicionado.

No teor de adição de $10 \%$, a separação das partículas já é suficiente para manter os níveis de atrito relativamente baixos e então para teores acima desse valor, a tendência é que a viscosidade da pasta governe o comportamento reológico da argamassa (CARDOSO, 2009). A viscosidade tende a aumentar com a adição de RCMG porque as partículas do resíduo possuem grande área superficial, absorvendo boa quantidade da água da mistura. Além disso, altos teores de resíduo adicionados aumentam a probabilidade de serem formados aglomerados, os quais elevam o atrito interno.

Pela melhora na fluidez, a adição de RCMG abre a possibilidade de usar uma menor relação água/cimento para que seja atingida a mesma fluidez da argamassa (ARNOLD; KAZMIERCZAK, 2009), informação que não pode ser obtida pelo ensaio do flow table. Uma menor relação água/cimento levaria a melhores desempenhos de resistência e durabilidade.

\section{CONCLUSÕES}

A partir da análise dos resultados obtidos, pode-se concluir que:

- A adição de RCMG não alterou significativamente o teor de ar incorporado, a densidade de massa e a retenção de água das argamassas no estado fresco para os teores estudados; 
- Os resultados dos índices de consistência apontam para uma leve redução da trabalhabilidade (aumento da consistência) das argamassas, que, no entanto, permaneceram em uma faixa igual a $290 \pm 10 \mathrm{~mm}$;

- O squeeze flow constitui-se em um método mais eficiente para a avaliação da reologia das argamassas, uma vez que são avaliados parâmetros mais próximos aos observados na aplicação do material;

- É necessária uma carga inferior de espalhamento das argamassas contendo até 10\% de RCMG como adição, o que evidencia um melhor empacotamento das partículas;

- A queda da fluidez observada para teores de adição acima de $10 \%$ pode ter sido causada pelo aumento da viscosidade da pasta decorrente da absorção de água pelas finas partículas do resíduo e pela formação de aglomerados do resíduo.

- Os resultados confirmam a viabilidade da adição de RCMG em argamassas, com a possibilidade de redução da relação água/cimento, o que pode melhorar as propriedades do estado endurecido, assim como a durabilidade;

- Em função das propriedades das argamassas no estado fresco, incluindo a reologia, aponta-se 10\% como teor ótimo de adição.

\section{REFERÊNCIAS}

ÂNGULO, Sérgio Cirelli; ZORDAN, Sérgio Edurado; JOHN, Vanderley Moacyr. Desenvolvimento sustentável e a reciclagem de resíduos na construção civil. Universidade de São Paulo, São Paulo, 2001. Disponível em: <http://www.reciclagem.pcc.usp.br/ftp/artigo\%20iv_ct206_2001.pdf>. Acesso em: 15 abr. 2013.

APOLINÁRIO, E; MATTA, V; RIBEIRO, D. Efeito da adição do resíduo de corte de mármore e granito (RCMG) nas propriedades das argamassas de revestimento.

Congresso Brasileiro de Engenharia e Ciência dos Materiais. Disponível em: <http://cbecimat.com.br/resumos/trabalhos_completos/104-003.doc>. Acesso em: 15 abr. 2013.

ARNOLD; KAZMIERCZAK. Influência da distribuição granulométrica e do agregado miúdo e do teor de fíler nas propriedades de argamassas com areia de britagem. VIII Simpósio 
Brasileiro de Tecnologia das Argamassas. Curitiba, 2009. Disponível em: <http://www.dcc.ufpr.br/mediawiki/images/8/82/TC034_Marienne_Artigo_Granulometria.pd f: Acesso em: 10 jun. 2013.

BANFILL, P. F. G. The rheology of fresh cement and concrete. Rheology Reviews. 2006, p.91-130.

BANFILL, P. F. G. The rheology of fresh mortar - a review. VI Simpósio Brasileiro de Tecnologia das Argamassas, Florianópolis, 2005 . p.73-82,

CARASEK, H. Materiais de Construção Civil e Princípios de Ciência e Tecnologia de Materiais - Volume 2. São Paulo: IBRACON, 2007. p.863-904.

CARDOSO, F. Método de formulação de argamassas de revestimento baseado em distribuição granulométrica e comportamento reológico. São Paulo, 2009. 138p. Tese de Doutorado - Departamento de Engenharia de Construção Civil, Escola Politécnica da Universidade Federal de São Paulo.

CARDOSO, F; PILEGGI, R.; JOHN, V. Caracterização reológica de argamassa pelo método de squeeze-flow. VI Simpósio Brasileiro de Tecnologia de Argamassas, p 121143, Florianópolis, 2005.

IBGE, 2010. Indústria da construção - Análise dos resultados. Disponível em: <http://www.ibge.gov.br>. Acesso em: 15 abr. 2013.

MANHÃES \& HOLANDA. Caracterização e classificação de resíduo sólido "pó de rocha granítica" gerado na indústria de rochas ornamentais. Quimica Nova, v.31, n.6, p.13011304, 2009.

PILEGGI, R. Ferramentas para o estudo e desenvolvimento de concretos refratários. São Carlos, 2001. 187p. Tese de Doutorado - Programa de Pós-Graduação em Ciência e Engenharia de Materiais, Universidade Federal de São Carlos.

RIBEIRO, D.V.; SILVA, A.S; LABRINCHA, J.A.; MORELLI, M.R.. Rheological properties and hydration behavior of Portland cement mortars containing calcined red mud.

Canadian Journal of Civil Engineering, v. 40, p. 557-566, 2013.

SENFF, L.; HOTZA, D.; REPETTE, W.L. Comportamento reológico de pastas de cimento com adição de sílica ativa, nanossílica e dispersante policarboxílico. Revista Matéria, vol.15, n.1, 2010.

SJÖSTRÖM, Ch. Durability and sustainable use of building materials. Sustainable use of materials. J.W. Llewellyn \& H. Davies editors. London, BRE/RILEM, 1992 